Lep. Rev. (1968) 39, 3, 127-133

\title{
The Anti-Inflammatory Effect of Indomethacin in Lepromatous Leprosy
}

\author{
INDER SINGH, M.B. (RANGOON), F.R.C.P.E., F.R.C.P. (GLASG.), F.A.M.S. \\ Senior Consultant in Medicine to the Armed Forces \\ M. C. SRIVASTAVA, M.D. (POONA) \\ Medical Specialist \\ L. C. ANAND, M.B.B.S., D.V.D. (вомвAY) \\ Dermatologist \\ From the Directorate General, Armed Forces Medical Services, New Delhi, 11, India
}

There is growing evidence that the antiinflammatory effect of indomethacin originally described in the inflammatory phases of rheumatoid disease, gout, psoriatic arthritis and the inflammatory complications of degenerative joint disease is widely distributed in the body. Thus indomethacin causes a moderate reduction in the size of the lymph nodes in Hodgkin's disease (Begemann et al., 1966) and benefits subacute and chronic recurrent inflammation of the uterine adnexa (Mehring et al., 1966). It prevents post-operative facial oedema after extraction of teeth (Mathis and Kempfle, 1966), and post-operative oedema following fractures of and operation on limbs (Penners, 1966). In animal experiments it has been found to have a favourable effect on the regenerative wound healing phase (Struck, 1966).

Equally interesting are the results obtained with indomethacin in skin diseases. Successful results have been obtained in herpes zoster, herpes simplex, varicella, parapemphigus and chronic benign familial pemphigus. A useful anti-inflammatory effect has also been noted in chronic lupus erythematosus discoides, Boeck's disease, pemphigus vulgaris and cicatrizing mucosal pemphigus. Erythema multiforme exudativum bullosum and occasionally vesiculation in lichen ruber, erysipelas and mycosis fungoides have been favourably affected (Herzberg and Heyl, 1966).

Therefore, in a planned trial we led ourselves to assess (1) whether indomethacin has an antiinflammatory effect in lepromatous leprosy, and (2) if so, whether indomethacin would hasten the rate of bacterial clearance by anti-leprotic drugs. The results of the first phase of the trial are reported in this paper.

\section{MATERIALS AND METHOD}

The patients were 20 Indians, all males, service personnel, 23 to 40 years old. The duration of lepromatous leprosy was 1 to 10 months in 19 of the patients and 18 months in the twentieth. They were all bacteriologically positive.

An initial estimate of the clinical condition of each patient comprising the type and extent of lesions found, bacteriological state, lepra reactions, haemoglobin, total and differential leucocyte count, erythrocyte sedimentation rate, and urine examination was made. The skin smears for lepra bacilli were obtained by Wade's scraped incision procedure from several sites and the drop obtained was deposited on a clean slide, dried and stained with Ziehl-Neelson's stain. Nasal scrapings were made over the nasal septum and treated the same way.

The trial, which was controlled but not blind, then commenced. As far as possible all comparable patients were paired by randomization. One in each pair received Treatment A, the other Treatment A plus Treatment B. Treatment A consisted of Dapsone with an initial test dose of 
TABLE

Details of individual results in 10 patients after 4,8 and 12 weeks of Treatment A plus Treatment B

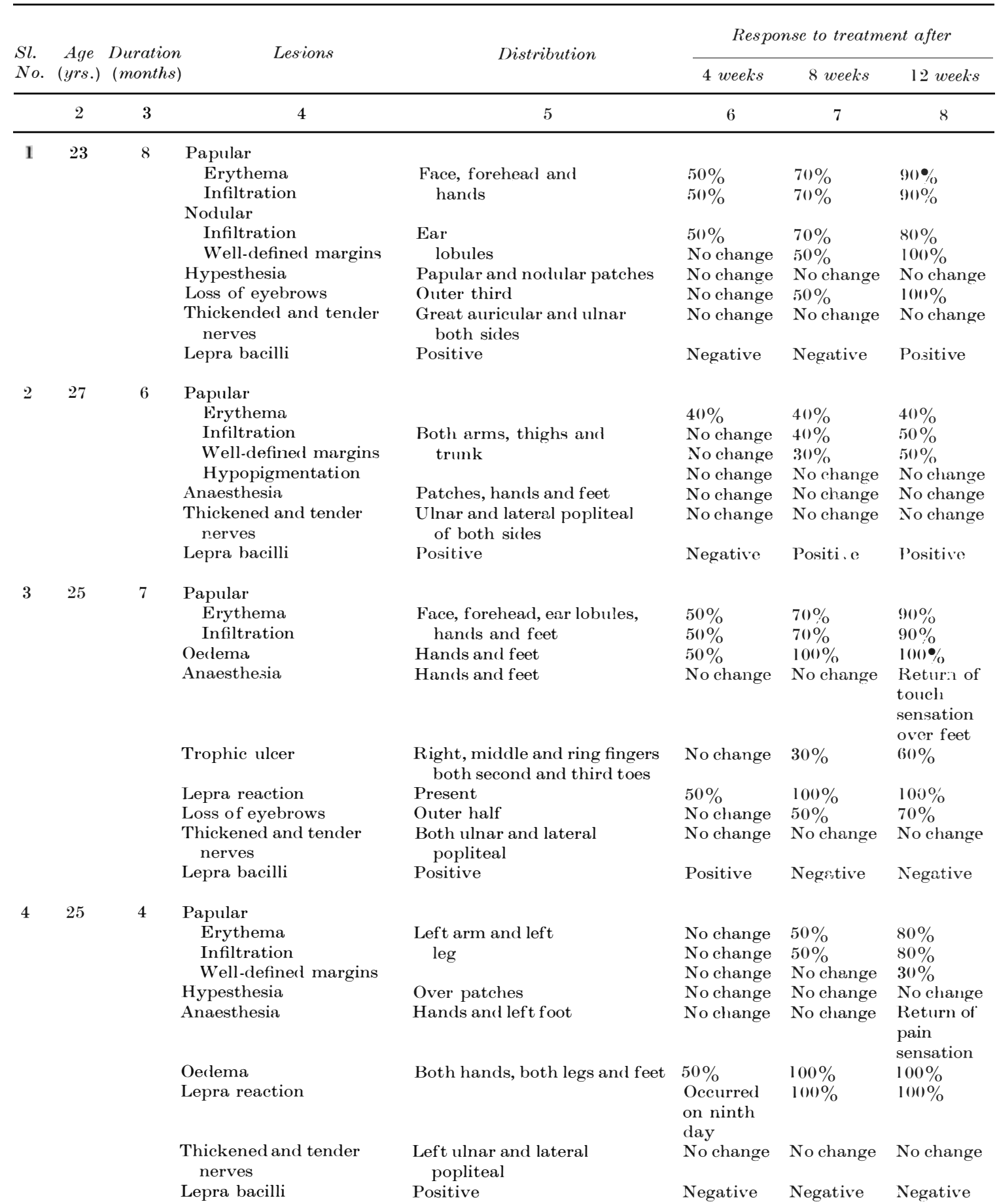




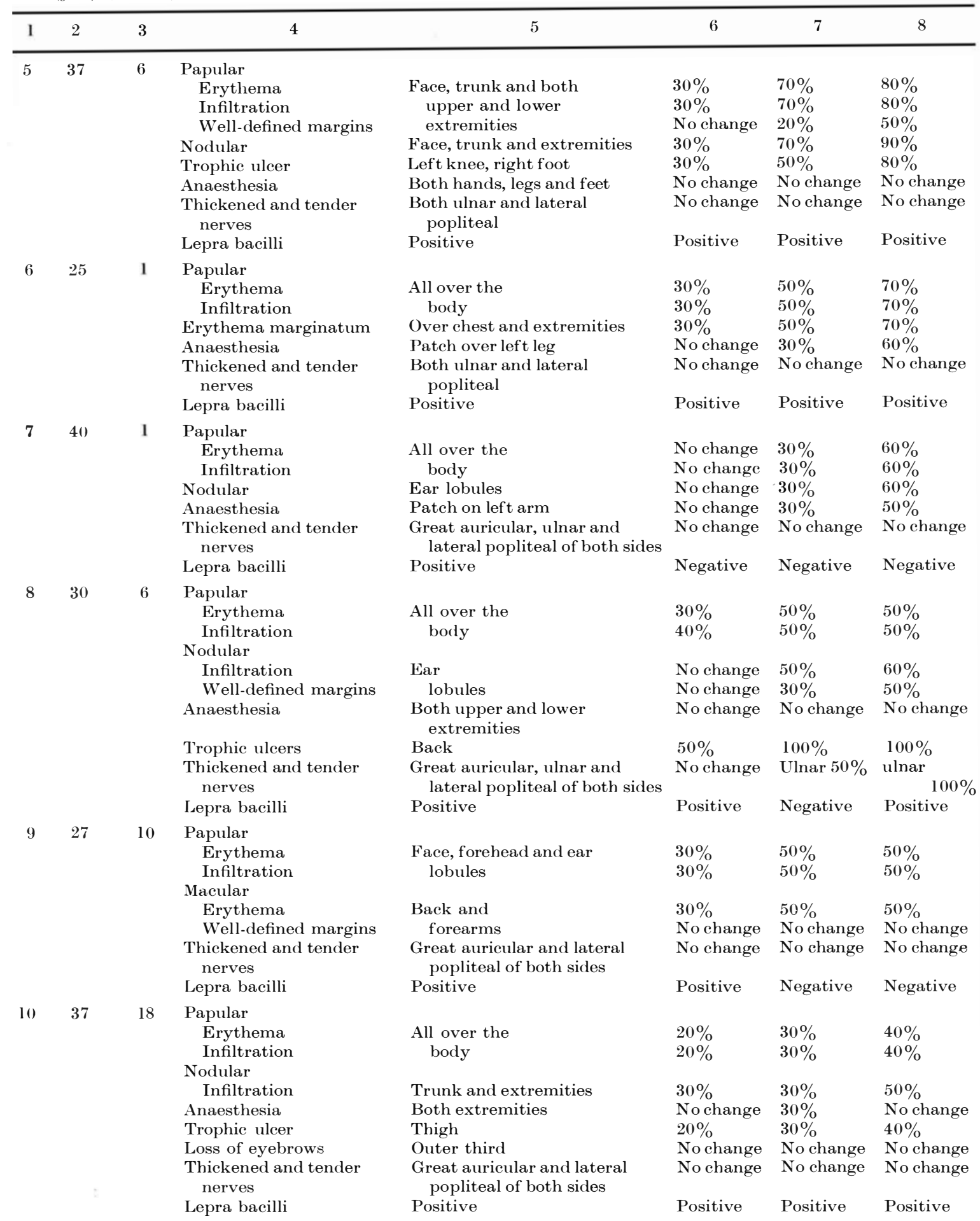


TABLe 2

Details of individual results in 10 patients after 4,8 and 12 weeks of Treatment A

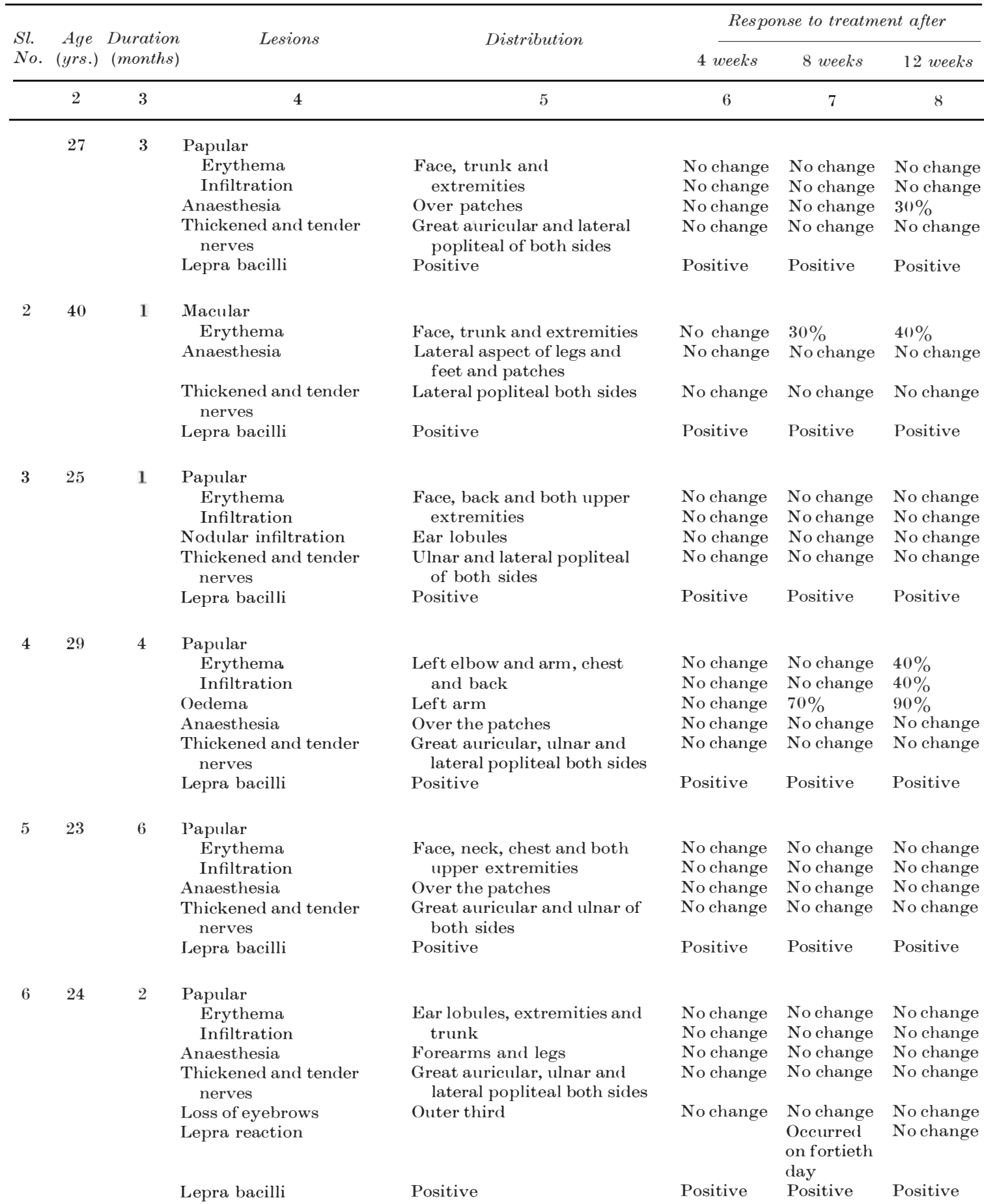




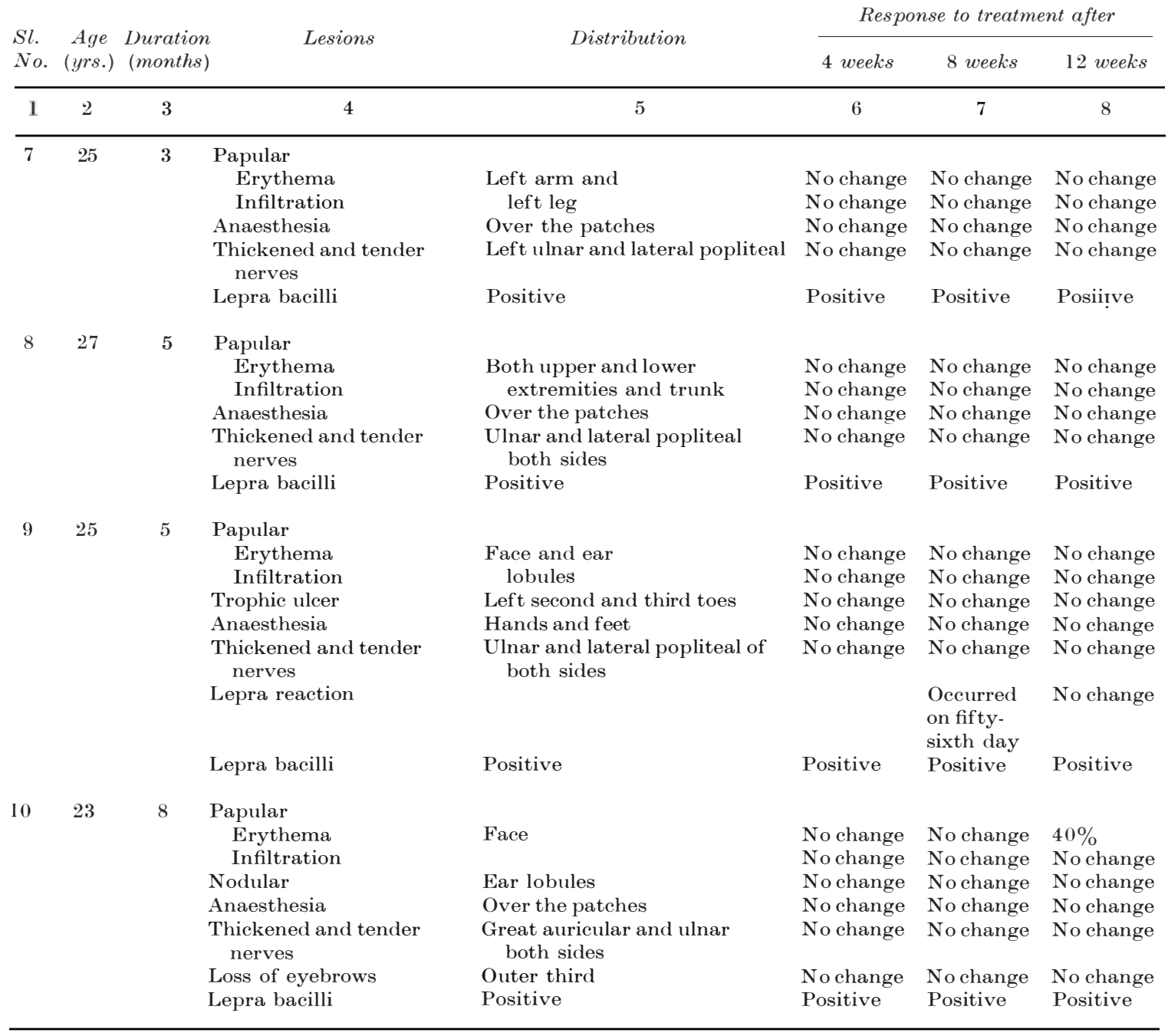

$10 \mathrm{mgm}$., followed by $25 \mathrm{mgm}$. daily for 6 days in the first week, $50 \mathrm{mgm}$. daily for 6 days in the second week, $75 \mathrm{mgm}$. daily for 6 days in the third week, and $100 \mathrm{mgm}$. daily for 6 days in a week indefinitely. Treatment B consisted of indomethacin $50 \mathrm{mgm}$. in capsules 3 times a day. The dosage of indomethacin was increased gradually over 3 to 6 days to avoid intolerance.

During treatment an estimate of the clinical condition was made every 4 weeks for 12 weeks. It was felt that whereas this was a reasonable period for assessment of any worthwhile antiinflammatory effect of indomethacin, it was not too long to influence the results by itself.
The recession, if any, of various lesions including lepra reaction was recorded as maximum 71 to $90 \%$, moderate 51 to $70 \%$, minimum 31 to $50 \%$, and none less than $30 \%$. Bacteriological clearance was recorded as maximum if both nasal and skin smears were repeatedly negative, and none if continuously or intermittently positive.

The number of patients that would be required for a significant result remained a problem as facilities for work were limited by shortage of beds. We felt, however, that since we were testing primarily the anti-inflammatory effect of indomethacin, in spite of variations in 
TABLE 3

\section{Summary of the results in 10 patients of each pair after 12 weeks of Treatment A plus Treatment $B$ and Treatment $A$ respectively}

\begin{tabular}{|c|c|c|c|c|c|c|c|c|c|c|}
\hline \multirow[b]{2}{*}{ Lesions } & \multirow[b]{2}{*}{$\begin{array}{l}\text { Total } \\
\text { No. }\end{array}$} & \multicolumn{4}{|c|}{ Treatment $A$ plus Treatment $B$} & \multirow[b]{2}{*}{$\begin{array}{l}\text { Total } \\
\text { No. }\end{array}$} & \multicolumn{4}{|c|}{ Treatment $A$} \\
\hline & & $\begin{array}{c}\text { Maximum } \\
71-90 \%\end{array}$ & $\begin{array}{l}\text { Moderate } \\
51-70 \%\end{array}$ & $\begin{array}{c}\text { Minimum } \\
31-50 \%\end{array}$ & $\begin{array}{c}\text { None } \\
\text { Less than } \\
30 \%\end{array}$ & & $\begin{array}{c}\text { Maximum } \\
71-90 \%\end{array}$ & $\begin{array}{l}\text { Moderate } \\
51-70 \%\end{array}$ & $\begin{array}{l}\text { Minimum } \\
31-50 \%\end{array}$ & $\begin{array}{c}\text { None } \\
\text { Less than } \\
30 \%\end{array}$ \\
\hline Macular & 1 & Nil & Nil & 1 & Nil & 1 & Nil & Nil & 1 & Nil \\
\hline Papular & 10 & 4 & 2 & 4 & Nil & 10 & Nil & Nil & 1 & 9 \\
\hline Oedema & 2 & 2 & Nil & Nil & Nil & 1 & 1 & Nil & Nil & Nil \\
\hline Trophic ulcer & 4 & 2 & 1 & 1 & Nil & 1 & Nil & Nil & Nil & 1 \\
\hline Anaesthesia & 9 & Nil & 1 & 2 & 6 & 9 & Nil & Nil & Nil & 9 \\
\hline $\begin{array}{l}\text { Thickened and } \\
\text { tender nerves }\end{array}$ & 10 & Nil & Nil & 1 & 9 & 10 & Nil & Nil & Nil & 10 \\
\hline
\end{tabular}

type, extent, and severity of lesions in the paired groups, any obvious difference between patients on Treatment A and those on Treatment A plus Treatment B would emerge. Since both groups received Treatment $\mathrm{A}$ the difference in favour of Treatment B would be the result of its indomethacin component.

\section{RESULTS}

Table 1 gives details of individual patients, the type and extent of their lesions and the response after 4,8 and 12 weeks of Treatment A plus Treatment B.

Table 2 gives details of individual patients, the type and extent of their lesions and the response after 4, 8 and 12 weeks of Treatment $\mathrm{A}$.

Table 3 summarises the results obtained in all 10 patients of each group after 12 weeks of Treatment A plus Treatment B and Treatment A respectively according to the criteria of assessment defined above.

There is striking improvement with Treatment A plus Treatment B in respect of skin lesions, oedema, healing of ulceration, and regrowth of eyebrows. Anaesthesia and nerve involvement have shown negligible improvement but there is some indication that improvement in these parameters may have occurred in time with further treatment. Bacteriological positivity has been favourably affected in 4 out of 10 patients which is considered significant for the period under observation.

One patient (Serial No. 4) under Treatment A plus Treatment B had a severe lepra reaction on the 9 th day of treatment. It was associated with fever, joint pains, swelling of both legs and arms, appearance of fresh erythematous patches over forearms, hands and legs, with thickening and tenderness of both ulnar nerves followed by wasting of small muscles of the hands. The treatment was continued without alteration of dosage. The effects of reaction subsided completely in 7 weeks.

Two patients (Serial Nos. 6 and 9) under Treatment A had lepra reactions. Serial No. 6 had a comparatively mild reaction with fever and appearance of new patches all over the body on the 40th day of treatment. Serial No. 9 had a more severe reaction with swelling of hands and feet and fresh patches all over the body, mainly the trunks, on the 56th day of treatment. The treatment was continued without alteration of dosage. The effects of the reactions were unaffected during the remaining period of observation. 


\section{DISCUSSION}

In lepromatous leprosy the dense granulomatous inflammatory reaction which occurs at the site of the infection fails to destroy the bacilli or to anchor the infection. Infection spreads to other parts of the skin via the tissue fluids and the lymph, to the peripheral nerves via their axonal pathways, and to distant organs via the lymph and the blood vessels. Resolution is by fibrosis and local blood vessels may be occluded by the process of obliterative endarteritis. The inflammatory reaction is therefore passive and useless. We feel, by its very nature, the inflammation is possibly responsible for the slow action of anti-leprotic drugs. The results which we have obtained so far in the trial seem to indicate that this is really so.

The granulomatous inflammatory reaction in the skin in lepromatous leprosy consists mostly of mononuclear cells and a few lymphocytes and plasma cells. To what extent this is reversed will become evident only in the histological studies which we are now carrying out.

Although axonal filaments are invaded by lepra bacilli there is no cellular infiltration within them. Hence they do not suffer from structural damage. The loss of hair and sensation apparently results from their involvement in the surrounding skin inflammation and have shown signs of return under indomethacin treatment.

Oedema of hands and feet which may be due to inflammatory reaction within the lymphatics, or their involvement in the skin inflammation, and affection of the autonomic nerves also subsides during indomethacin treatment.

The acute inflammatory manifestations in reactional states involving skin lesions and nerves with or without oedema of the hands and feet seem to be benefited but not altogether prevented by indomethacin.

\section{SUMMARY}

In a controlled (but not blind) trial in 10 patients with bacteriologically positive lepromatous lepsory, within 12 weeks indomethacin produced striking improvement in respect of skin lesions, oedema of limbs, healing of ulcers, and regrowth of eyebrows. Anaesthesia and nerve involvement showed negligible response, although comparison of the 2 groups of patients indicates that improvement in these parameters may occur in time with further indomethacin treatment. Four of the 10 patients on indomethacin became bacteriologically negative which is considered significant for the period of treatment. The effects of a severe lepra reaction which occurred within 10 days of indomethacin treatment subsided completely within 7 weeks under continued treatment with the drug.

\section{ACKNOWLEDGEMENT}

We are grateful to Lieut.-General J. R. Vaid, Director General, Armed Forces Medical Services, for permission to publish this paper.

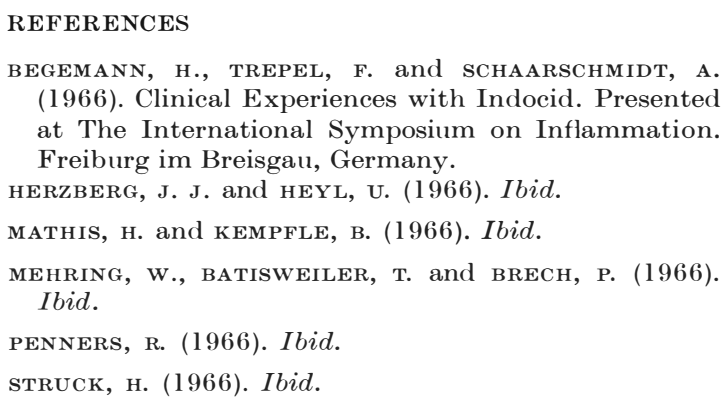

